\title{
Investigation of rechargeable lithium-sulfur batteries by in-situ techniques
}

Natalia A. Cañas ${ }^{1,2}$, Kei Hirose ${ }^{1}$, Brigitta Pascucci ${ }^{1}$, Norbert Wagner ${ }^{1}$, K. Andreas Friedrich ${ }^{1,2}$, Renate Hiesgen ${ }^{3}$

${ }^{1}$ German Aerospace Center, Stuttgart, Institute of Technical Thermodynamics Pfaffenwaldring 38-40, 70569, Germany

2 University of Stuttgart, Institute for Thermodynamic and Thermal Engineering, Pfaffenwaldring 6, 70569, Germany

3 University of Applied Sciences Esslingen, Department of Basic Science, Kanalstrasse 33, 73728 Esslingen, Germany

\section{Lithium-sulfur battery}

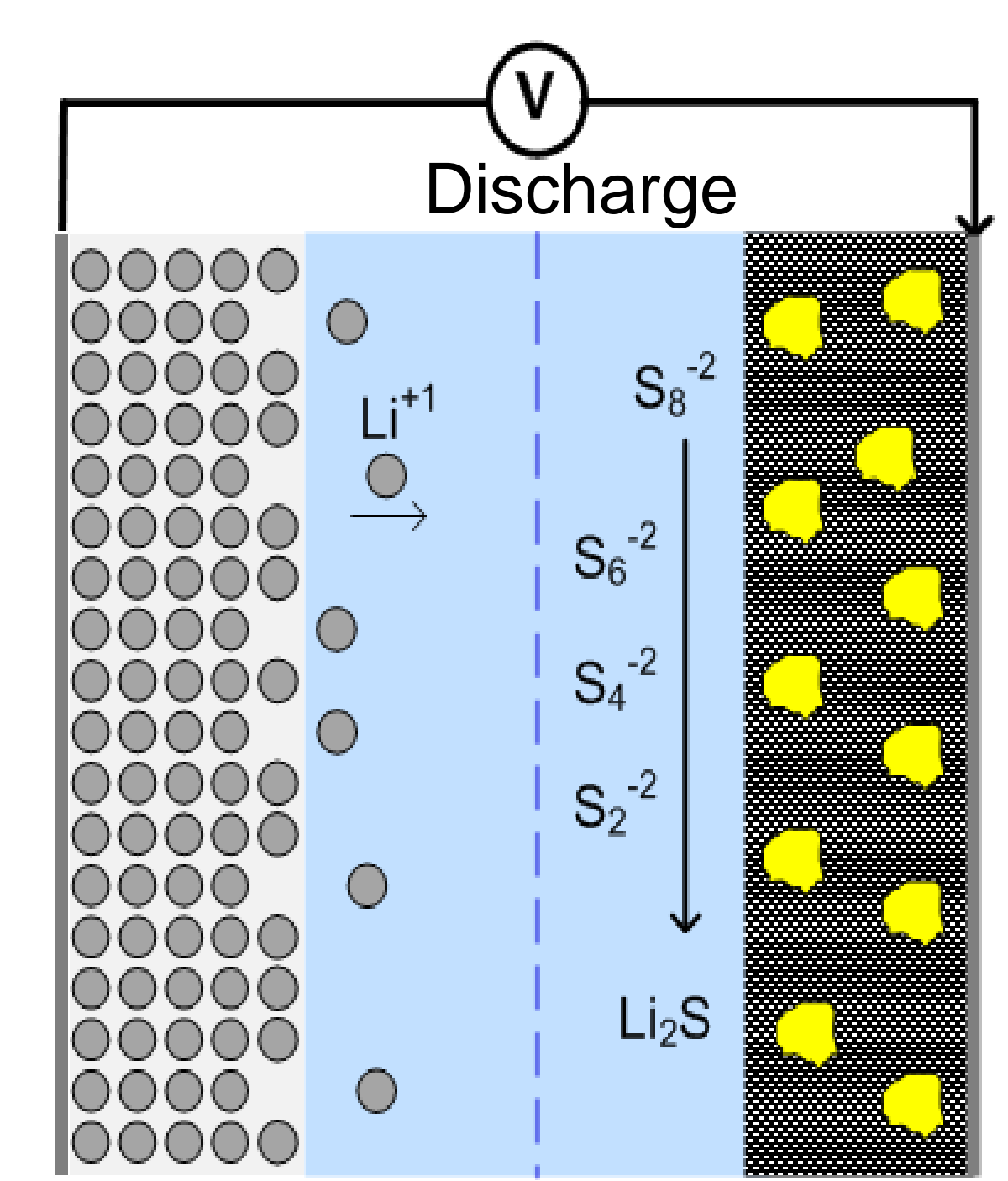

Electrochemical reactions

\begin{tabular}{|c|c|c|}
\hline & $S_{8(s)}$ & $\rightarrow \mathrm{S}_{8 \text { (diss) }}$ \\
\hline $1 / 2 S_{8(\text { diss) }}$ & $+\mathrm{e}^{-}$ & $\rightarrow 1 / 2 S_{8}$ \\
\hline $3 / 2 \mathrm{~S}_{8}^{-2}$ & $+\mathrm{e}^{-}$ & $\rightarrow 2 \mathrm{~S}_{6}^{-2}$ \\
\hline $\mathrm{S}_{6}^{-2}$ & $+\mathrm{e}^{-}$ & $\rightarrow 3 / 2 S_{4}$ \\
\hline $3 / 2 S_{4}^{-2}$ & $+\mathrm{e}^{-}$ & $\rightarrow 2 \mathrm{~S}_{3}^{-2}$ \\
\hline $\mathrm{S}_{3}^{-2}$ & $+\mathrm{e}^{-}$ & $\rightarrow 3 / 2 S_{2}$ \\
\hline $1 / 2 S_{2}^{-2}$ & $+\mathrm{e}^{-}$ & $\rightarrow \mathrm{S}^{-2}$ \\
\hline $2 \mathrm{Li}^{+1}$ & $+S^{-2}$ & \\
\hline
\end{tabular}

high theoretical capacity (1675 $\left.\mathrm{Ah} \mathrm{kg}_{\text {sulfur }}{ }^{-1}\right)$

high energy density $\left(2500 \mathrm{Wh} \mathrm{kg}^{-1}\right)$

low cost and non-toxicity of sulfur

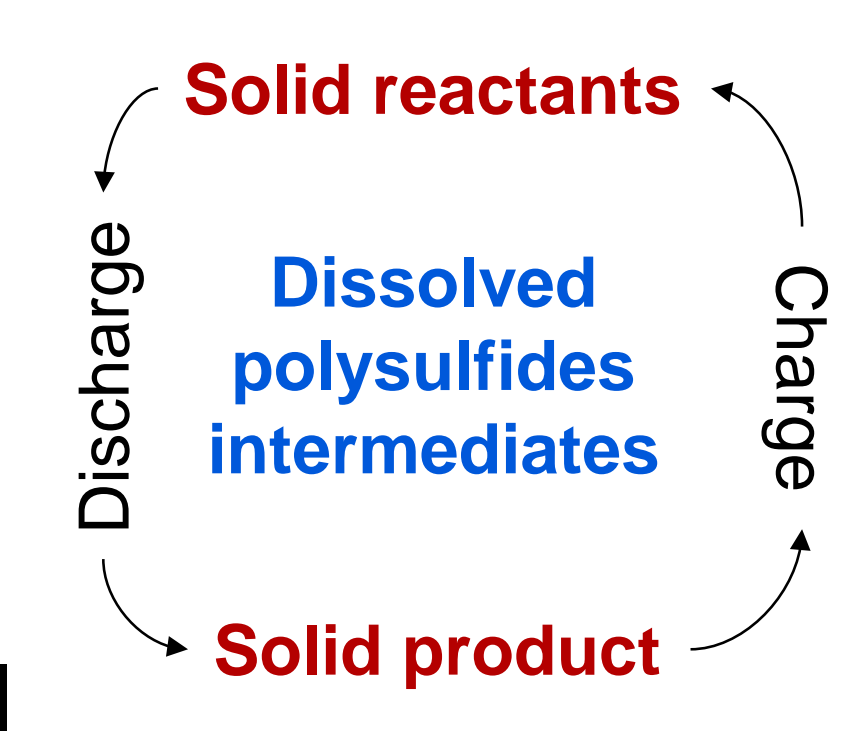

high degradation due to loss of active materia

- electrochemical processes and degradation mechanisms are still not well understood.

\section{Materials and methods}

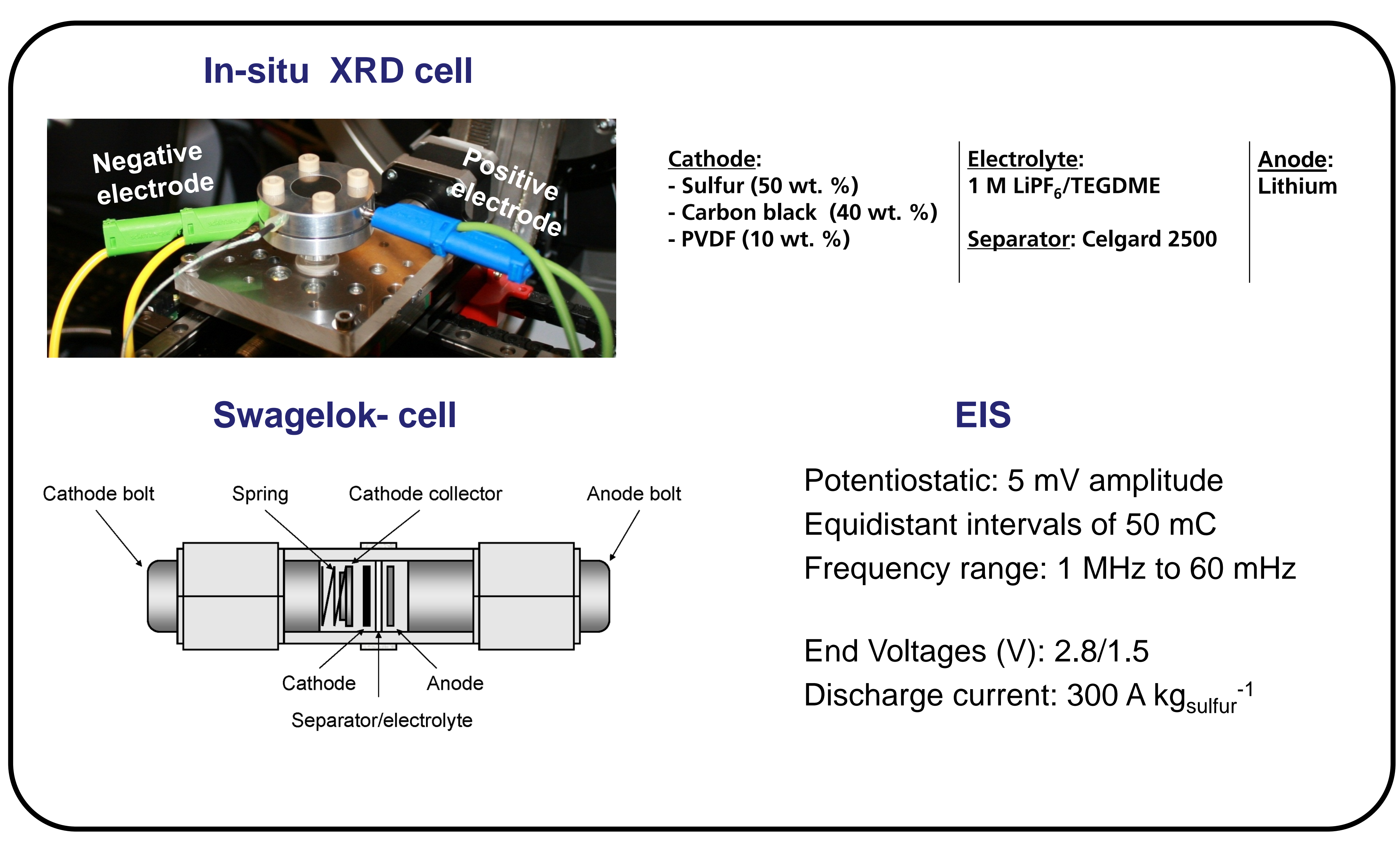

Results

In-situ X-ray analysis

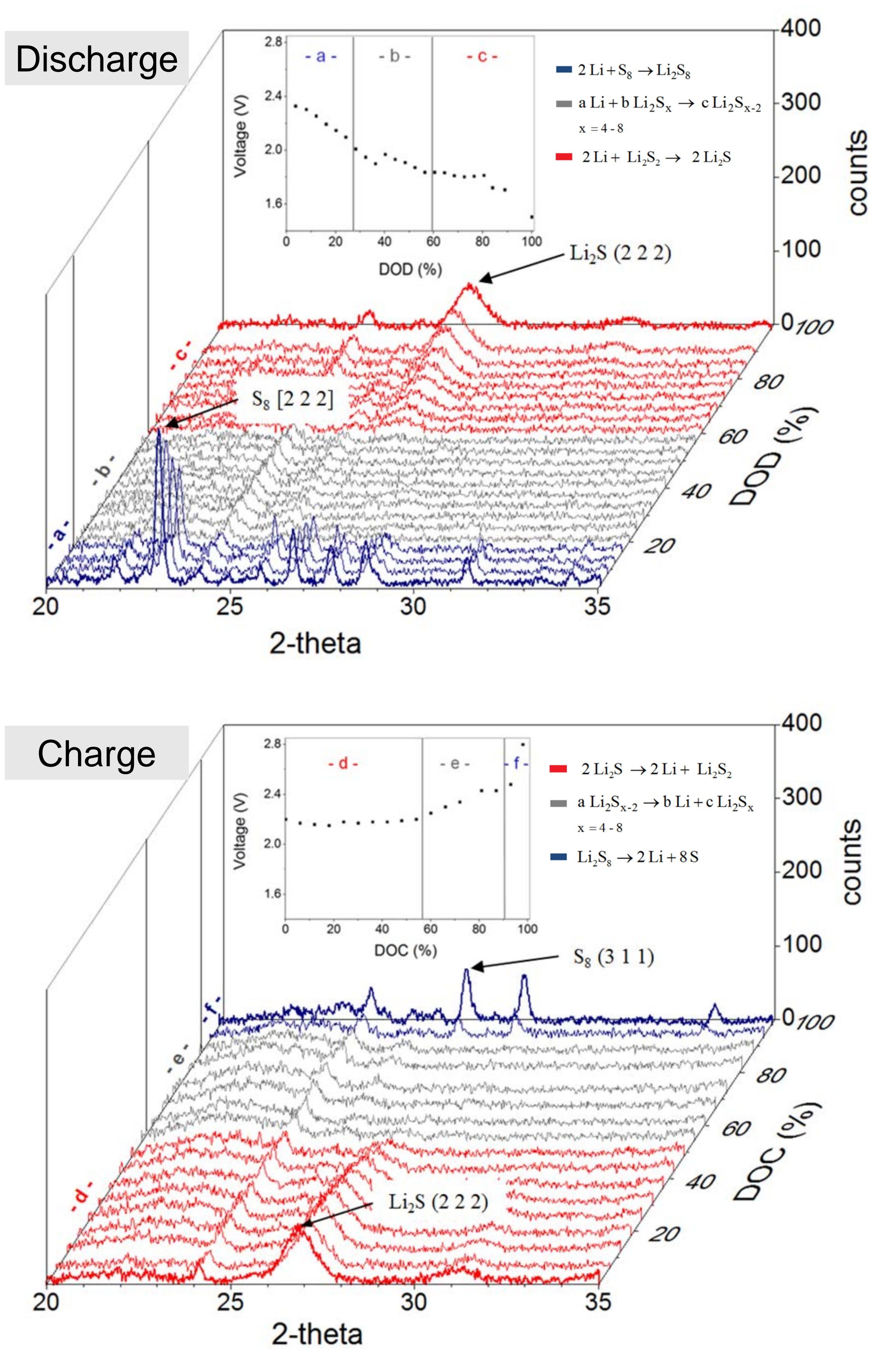

- At discharge rate of $300 \mathrm{~A} \mathrm{~kg}^{-1}$ sulfur reduces consecutively during the first discharge to $\mathrm{Li}_{2} \mathrm{~S}$.

- The formation of $\mathrm{Li}_{2} \mathrm{~S}$ was observed for the first time at a depth of discharge of $60 \%$ in the second discharge plateau at $1.8 \mathrm{~V}$.

- During the charge cycle, $\mathrm{Li}_{2} \mathrm{~S}$ reacts entirely and sulfur recrystallizes with a different orientated structure and smaller particle size [1].
Electrochemical Impedance Spectroscopy

Variation of the equivalent circuit elements during cycling determined by EIS analysis.
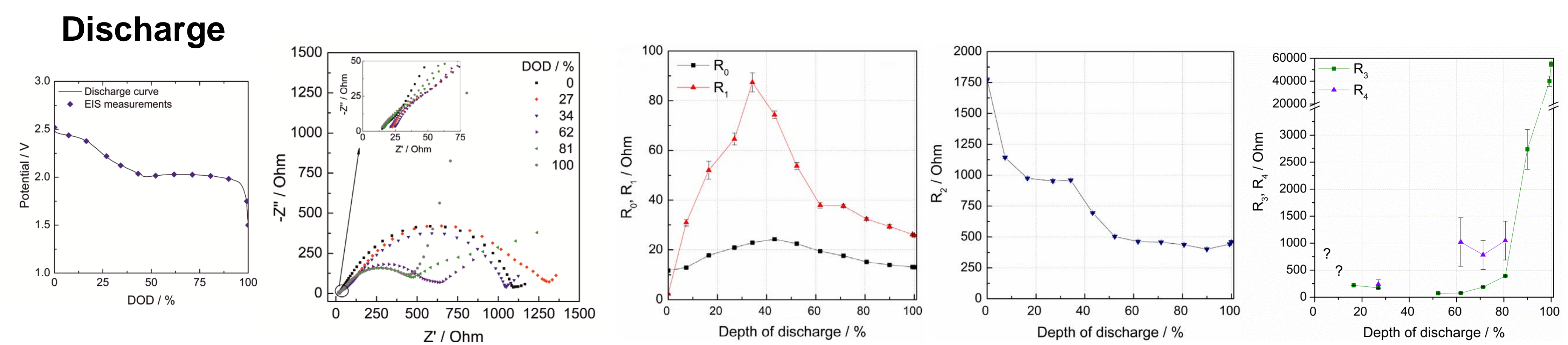

\section{Charge}
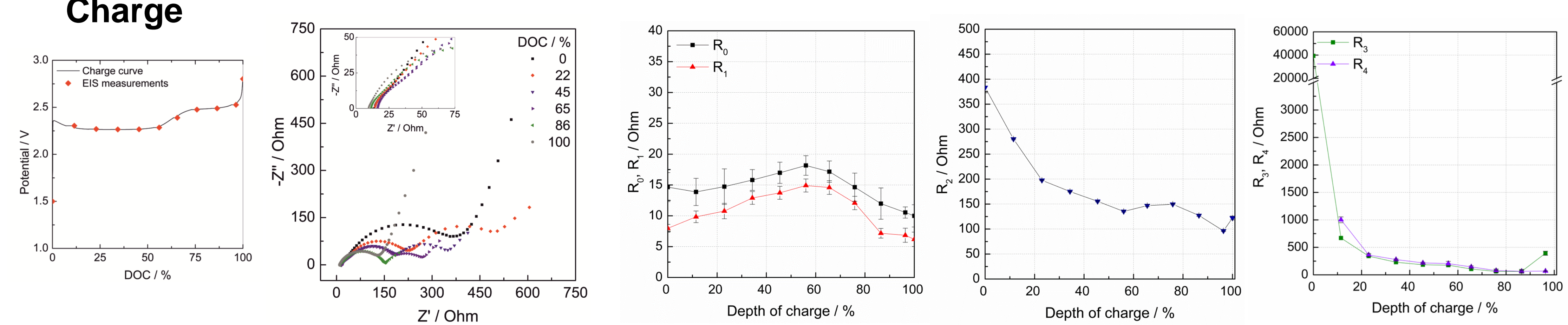

- The highest electrolyte resistance, related to the highest concentration of polysulfides is detected at the end of the first discharge and charge plateau (43\% DOD and $56 \%$ DOC)

- The impedance contributions associated to the processes in the cell are strongly dependent on the depth of discharge and charge of the cell [2].

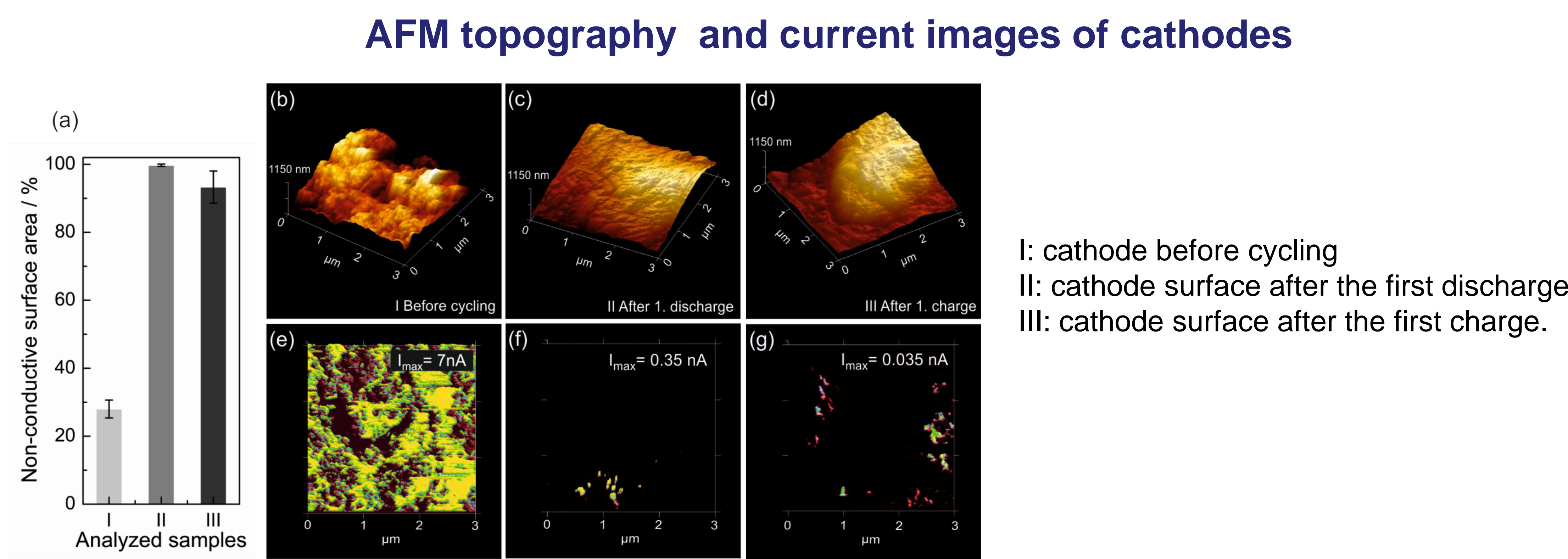

The AFM results confirm the formation of an isolating layer in the cathode, which increases the surface resistance on the cathode, as observed through the analysis of the impedance at low frequencies $\left(R_{3}\right)$.
References

[1] N. A. Cañas, S. Wolf, N. Wagner, K. A. Friedrich. J. of Power Sources, 226 (2013) 313-319

[2] N. A. Cañas, K. Hirose, N. Wagner, B. Pascucci, K.A Friedrich, R. Hiesgen. Electrochimica Acta, 97 (2013) 42-51.

\section{Deutsches Zentrum}

DLR für Luft- und Raumfahrt

German Aerospace Center 